\title{
Treatment of Atypical Clots
}

\author{
Walter Ageno ${ }^{1}$ \\ ${ }^{1}$ Department of Medicine and Surgery, University of Insubria, Varese, \\ Italy \\ Hamostaseologie 2022;42:10-18. \\ Address for correspondence Walter Ageno, Department of Medicine \\ and Surgery, University of Insubria, Varese, Italy \\ (e-mail: walter.ageno@uninsubria.it).
}

\begin{abstract}
Keywords

- venous thrombosis

- unusual site thrombosis

- anticoagulation

- direct oral anticoagulants

The term unusual site thrombosis refers to the occurrence of venous thromboembolism outside of the lower limbs and the pulmonary arteries. Unusual site thrombosis can virtually affect any venous segment, with the most common and/or clinically relevant sites including the upper limbs veins, the retinal veins, the splanchnic veins and the cerebral veins. Clinical features are obviously heterogeneous, while many predisposing factors are common, though with different prevalence among the various disorders. Antithrombotic therapy is prescribed to most patients, but the type, intensity, and duration of treatment vary both within and among patient groups. Increasing evidence is supporting the use of the direct oral anticoagulants in patients with upper limb deep vein thrombosis, cerebral vein thrombosis, and with splanchnic vein thrombosis. This article will review available evidence on the treatment of venous thrombosis occurring in unusual sites.
\end{abstract}

Venous thromboembolism (VTE) usually occurs in the lower limbs and in the pulmonary arteries, representing the third most common cardiovascular disease. ${ }^{1}$ However, VTE may also occur in other venous segments, such as the veins of the upper limbs, the retinal veins, the abdominal and pelvic veins, and the cerebral veins. Each unusual site of thrombosis presents distinct features with regard to clinical presentation, underlying provoking factors (type and prevalence), and clinical outcomes and generally requires multidisciplinary approaches. Because of the relatively low incidence of these events, adequately sized clinical trials are lacking and evidence to support therapeutic decisions is scant. Therefore, clinicians usually need to translate evidence available for the management of patients with proximal deep vein thrombosis (DVT) of the lower limbs or pulmonary embolism (PE) to patients with VTE in these unusual sites, although this approach may sometimes become challenging. We here review available evidence on the treatment of VTE occurring in unusual sites.

\section{Upper Extremity Deep Vein Thrombosis}

Upper extremity DVT involves the brachial, axillary, subclavian, and jugular veins and can be associated with several provoking factors such as cancer, use of indwelling lines (e.g., central vein catheters), surgery, immobilization, strenuous physical activity in the presence of congenital or acquired anatomical abnormalities, and trauma. ${ }^{2}$ The results of observational studies suggest that patients with upper extremity DVT are at lower risk of PE and at lower risk of recurrence than patients with lower limb DVT. ${ }^{3-6}$ No randomized controlled trials have compared treatment strategies in these patients, but several studies including up to approximately 200 patients have reported on the safety and effectiveness of treatment with various anticoagulants. In particular, outcome rates appear to be similar between patients receiving standard of care with low-molecularweight heparin (LMWH) and vitamin $\mathrm{K}$ antagonists and patients receiving treatment with direct oral anticoagulants (DOACs). ${ }^{7-18}$ In a large international registry, anticoagulant treatment strategies were virtually identical between 438 patients with upper extremity DVT and 7,602 patients with lower extremity DVT, but the proportion of patients continuing anticoagulant treatment beyond 3 months was slightly lower in patients with upper extremity DVT than in patients with lower limb DVT (66 and 72\% at 6 months and 45.7 and $54.6 \%$ at 12 months, respectively). ${ }^{2}$ VTE recurrence received

August 21, 2021

accepted after revision

October 12, 2021 (c) 2022. Thieme. All rights reserved. Georg Thieme Verlag KG,

Rüdigerstraße 14,

70469 Stuttgart, Germany
DOI https://doi.org/ 10.1055/a-1669-3336. ISSN 0720-9355. 
rates (4.0 and 5.5 per 100 person-years, respectively) and major bleeding rates (1.3 and 1.6 per 100 person-years, respectively) were similar between the two groups. All-cause mortality rates were significantly higher in patients with upper extremity DVT than in patients with lower extremity DVT (9.7 and 6.7 per 100 person-years, respectively, $p=0.034$ ), likely because of a higher proportion of cancer patients in the former than in the latter group.

International guidelines on antithrombotic therapy suggest anticoagulation alone over thrombolysis followed by anticoagulant drugs for patients with acute upper extremity DVT, and suggest to consider thrombolysis in selected patients with severe symptoms, with thrombus involving most of the subclavian vein and the axillary vein, and with low risk of bleeding. ${ }^{19}$

It is also suggested that patients with DVT of the upper extremity should receive the same anticoagulant treatment regimens used for patients with DVT of the lower extremity, including the DOACs alone (apixaban and rivaroxaban), LMWH and DOACs (edoxaban and dabigatran), LMWH alone, or LMWH and vitamin $\mathrm{K}$ antagonists, according to underlying provoking factors, costs, and patient preferences. As for patients with lower limb DVT, anticoagulant treatment should be continued for at least 3 months and extended beyond 3 months if the event is unprovoked or secondary to permanent risk factors (e.g., cancer) and bleeding risk is low. The use of thrombolytic treatment or surgical approaches should be restricted to highly selected cases at low risk for bleeding. The use of compression sleeves to prevent the postthrombotic syndrome is suggested by some authors, but the efficacy of this strategy has not been confirmed by adequately designed clinical trials. ${ }^{20}$

\section{Splanchnic Vein Thrombosis}

Splanchnic vein thrombosis encompasses thrombosis of the portal vein, the mesenteric veins, the splenic vein, and the Budd-Chiari syndrome. Most common risk factors include liver cirrhosis, solid abdominal cancer, myeloproliferative neoplasms, infectious and inflammatory abdominal diseases, surgery, and trauma. ${ }^{21}$ Recurrence and bleeding rates widely vary according to underlying provoking factors, being highest in patients with liver cirrhosis and lowest in patients with splanchnic vein thrombosis secondary to transient risk factors such as surgery or infections. ${ }^{22}$ Anticoagulant therapy is the first line of treatment for splanchnic vein thrombosis. Before treatment is started, careful individual assessment of the bleeding risk is recommended, in particular in patients with liver cirrhosis and patients with solid or hematologic cancer. Most common risk factors for bleeding include esophageal varices, low platelet count, severe liver or renal failure, and concomitant therapies. Several observational studies have shown that early initiation of anticoagulation is associated with better vessel recanalization, which in particular can reduce the occurrence of portal-hypertension-related complications. ${ }^{23,24}$ Thus, anticoagulant therapy in patients with acute splanchnic vein thrombosis should be started early after diagnosis, if there is no active bleeding, ${ }^{25}$ to avoid the extension of the clot and promote vessel recanalization. If esophageal varices are present, implementation of adequate prophylaxis such as nonselective $\beta$-blockers or endoscopic variceal band ligation is recommended and full anticoagulation should be started after complete endoscopic variceal eradication is obtained, if required. ${ }^{25-28}$ Heparins represent the mainstay of treatment during the acute phase of disease. Due to its very short half-life and to the possibility to measure the anticoagulant effect with the activated partial thromboplastin time, unfractionated heparin is preferred in patients at very high bleeding risk, patients who are potentially candidates for surgery (e.g., for bowel infarction), and in patients with severe renal insufficiency. ${ }^{29}$ LMWH is administered as a stand-alone drug or followed by oral anticoagulants for the majority of patients. Administration of LMWH alone for the first weeks/months of treatment is preferred in patients with solid cancer, in particular gastrointestinal cancer, and in patients at high bleeding risk (e.g., patients with thrombocytopenia) thanks to the possibility to use individualized dose reductions (e.g., $50 \%$ dose reduction for platelet count between 30 and $50 \times 10^{3} / \mathrm{mm}^{3}$ and prophylactic doses for platelet count between 20 and $\left.30 \times 10^{3} / \mathrm{mm}^{3}\right) .{ }^{30}$ For all other patients, a switch to vitamin $\mathrm{K}$ antagonists is generally suggested, with a therapeutic international normalized ratio (INR) range between 2.0 and 3.0. Recently, the DOACs have become a possible alternative to vitamin $\mathrm{K}$ antagonists. Despite limited available evidence, a recent guidance document from the International Society on Thrombosis and Haemostasis (ISTH) has suggested the DOACs as the first line treatment for patients with nonmalignant and noncirrhotic splanchnic vein thrombosis. ${ }^{25}$ In cancerassociated thrombosis, LMWH or DOACs are preferred over vitamin $\mathrm{K}$ antagonists, because of their greater efficacy. ${ }^{31}$ LMWH should be preferred over the DOACs for patients with solid cancer at high bleeding risk (e.g., luminal gastrointestinal or genitourinary cancers) or in patients receiving ongoing treatments which might potentiate or reduce the effect of the DOACs. ${ }^{25}$ In cirrhosis-associated splanchnic vein thrombosis, the recent guidance of the ISTH suggests to start therapy with LMWH and to consider a switch to oral agents (either vitamin K antagonists or DOACs) only if not contraindicated by severe liver dysfunction. ${ }^{25}$ Finally, similar therapeutic strategies have been recently suggested for patients with symptomatic and patients with incidentally detected splanchnic vein thrombosis since several studies found no difference in recurrence rates between the two groups. ${ }^{25,32,33}$

Local or systemic thrombolysis is usually proposed to a limited number of patients with thrombus progression or worsening clinical conditions despite adequate anticoagulation or with bowel infarction. ${ }^{25,34}$

Anticoagulation should be given for a minimum of 3 to 6 months and continued indefinitely in patients at low bleeding risk with recurrent thrombosis, permanent risk factors, or unprovoked events. ${ }^{25,27,30,31,35}$

\section{Cerebral Venous Thrombosis}

Cerebral venous thrombosis (CVT) involves the cerebral veins, cortical and deep veins, and the dural venous sinuses, 
superior sagittal, lateral or transverse, straight, sigmoid, and cavernous. Most common risk factors include cancer, inflammatory disorders, trauma, hormonal therapy, pregnancy and puerperium, and thrombophilia. ${ }^{36}$ The high prevalence of these latter risk factors may explain the fact that CVT is typically associated with younger adults and is threefold more common in women than in men. ${ }^{36}$ Recurrent rates are lowest in young women with sex-specific risk factors and highest in older patients with permanent risk factors (e.g., cancer) or unprovoked events. ${ }^{37}$ As for any venous thromboembolic event, anticoagulant treatment constitutes the mainstay of management, while loco-regional thrombolytic therapy is reserved for selected patients with severe conditions which deteriorate despite anticoagulant treatment. ${ }^{38}$ The randomized prospective TO-ACT (Thrombolysis or Anticoagulation for Cerebral Venous Thrombosis) trial was intended to assess the safety and efficacy of endovascular treatment versus anticoagulation alone in patients with severe CVT and was prematurely terminated due to futility, no difference in the proportion of patients with a favorable clinical outcome between the two treatment groups. ${ }^{39}$

International guidelines recommend initial parenteral anticoagulation with unfractionated heparin or LMWH, also for patients with hemorrhagic infarcts. ${ }^{38,40}$ Based on the results of a nonrandomized study that suggested better safety and efficacy of LMWH over unfractionated heparin, the former is recommended for the majority of patients as the first line of treatment, the latter should be preferred in high-risk patients such as those presenting with intracerebral bleeding. Stable patients are switched to vitamin $\mathrm{K}$ antagonists with a therapeutic range of INR 2 to $3 .^{38,40}$ Recently, the potential use of DOACs as an alternative to vitamin $\mathrm{K}$ antagonists was proposed. The RE-SPECT CVT was a randomized open-label clinical trial that compared dabigatran etexilate with warfarin after an initial 5 to 15 day treatment with heparins for the prevention of VTE recurrence in 120 patients with CVT. ${ }^{41}$ No recurrent events were observed in either group, recanalization rates were comparable, and the risk of bleeding was similar between the two study arms. Data on other DOACs such as apixaban and rivaroxaban are limited to case series. ${ }^{36}$

A treatment duration of 3 to 12 months is suggested, with a shorter duration (3-6 months) to be considered for CVT patients with a known transient risk factor and a longer treatment duration for patients with unprovoked events. ${ }^{38}$ Finally, patients with persistent risk factors should receive an indefinite treatment duration. An ongoing trial (EXCOA-CVT) is comparing the efficacy and safety of short-term (3-6 months) versus longterm (12 months) anticoagulant treatment for CVT. ${ }^{42}$

\section{Retinal Vein Occlusion}

Retinal vein occlusion, which includes central and branch retinal vein thrombosis, is a leading cause of visual loss. Local risk factors act by favoring venous stasis, such as in the case of open angle glaucoma, or increasing intraocular pression. ${ }^{43}$ Several systemic risk factors have been identified, but their association with venous occlusion still remains uncertain.
These include advanced age, hypertension, diabetes, dyslipidemia, and thrombophilia. The risk of recurrence is not negligible, as much as the risk of subsequent cardiovascular events. ${ }^{44}$ Ophthalmologic treatment mainly aims at preventing local neovascular complications, and includes the use of intravitreal steroids and anti-VEGF (vascular endothelial growth factor) agents, laser therapy, and several surgical options in selected patients, including vitrectomy, sheathotomy, and radial optic neurotomy. ${ }^{45,46}$ International guidelines also suggest to optimize the management of major systemic risk factors, such as hypertension, diabetes, and dyslipidemia, when identified. ${ }^{45,46}$ The use of antithrombotic treatment has also been proposed. ${ }^{47}$ Despite limited evidence, the use of LMWH in selected patients with recent onset of symptoms (i.e., less than 15 days) may be considered, as well as the use of aspirin for the long-term treatment of patients with retinal vein occlusion and concomitant cardiovascular risk factors. ${ }^{47}$

A systematic review and meta-analysis of three randomized controlled trials comparing LMWH with aspirin in a total of 229 patients with acute retinal vein occlusion showed that patients receiving heparin had a better improvement in visual acuity and a significantly lower risk of developing any adverse ocular outcome. ${ }^{48}$ There is also some evidence suggesting a possible role of antiplatelet agents in preventing recurrence of retinal vein occlusion. ${ }^{49,50}$

No study has explored the use of the DOACs for the treatment of retinal vein occlusion.

\section{Inferior Vena Cava Thrombosis}

In most cases, thrombosis of the inferior vena cava (IVC) originates from the extension of proximal DVT of the lower limbs. Less commonly, isolated IVC thrombosis is diagnosed, in particular in patients with cancer and in patients with atresia or other abnormalities of the ICV. There is very limited evidence to drive therapeutic decisions for patients with IVC thrombosis and, generally, the same treatment approaches as for proximal DVT of the lower limbs are suggested. For selected patients, though, the use of catheter-directed thrombolysis or pharmaco-mechanical catheter-directed thrombolysis has also been proposed, but evidence is largely derived from studies that did not include patients with isolated IVC thrombosis. $^{51-54}$ In one of the few studies reporting on short-term clinical outcomes in IVC thrombosis, a nonnegligible proportion of patients received catheter-directed thrombolysis, but also balloon angioplasty and stenting, with apparently no benefits in terms of mortality in comparison with standard anticoagulation. ${ }^{55}$

\section{Renal Vein Thrombosis}

The occurrence of renal vein thrombosis has been reported in patients with nephrotic syndrome, renal cancer, renal infections or trauma, with extrinsic compression, or after renal transplant surgery ${ }^{56}$ Thrombus extension to the vena cava is not uncommon. Evidence on the treatment of renal vein thrombosis is mainly based on case reports or small case 
series. Patients generally receive anticoagulant treatment, typically with unfractionated heparin or LMWH followed by warfarin. LMWH alone is preferred over warfarin in patients with renal cancer. Information on recurrence rates is lacking, duration of treatment should follow the same rules applied for patients with usual-site thrombosis. In principle, the management of the underlying cause is expected to influence the long-term risk of recurrence.

\section{Ovarian Vein Thrombosis}

Ovarian vein thrombosis is associated with the postpartum period, ovarian cancer, pelvic inflammatory disease, and pelvic surgery. ${ }^{57}$ Anticoagulant treatment with heparins and vitamin $\mathrm{K}$ antagonists is generally prescribed, but only small cohort studies are available, mainly conducted in women with postpartum ovarian vein thrombosis. ${ }^{58}$ As for other unusual sites of thrombosis, treatment decisions are usually based on evidence from trials conducted in patients with lower limb DVT and treatment duration based on the removable or permanent nature of provoking risk factors.

\section{Conclusions}

The management of atypical clots is usually based on anticoagulant regimens recommended for patients with usual-site vein thrombosis, i.e., lower limb DVT and PE. The application of these regimens requires a careful, individual assessment of the risk of recurrence, bleeding, and short- and long-term outcomes. Factors that influence these risks mainly include the site of thrombosis and the presence of specific underlying risk factors. Evidence to support these decisions mainly originates from often small and retrospective observational studies. Since randomized clinical trials will always be hard to complete in these settings due the low incidence and also the heterogeneity of these diseases, multicenter, international collaborations should be pursued to run sufficiently large observational prospective cohort studies. These studies will provide useful information and support the validity of translating evidence from usual-site to unusual-site VTE.

\section{Conflict of Interest}

The author declares that he has no conflict of interest.

\section{References}

1 Lindblad B, Sternby NH, Bergqvist D. Incidence of venous thromboembolism verified by necropsy over 30 years. BMJ 1991;302 (6778):709-711

2 Ageno W, Haas S, Weitz JI, et al. Upper extremity DVT versus lower extremity DVT: perspectives from the GARFIELD-VTE registry. Thromb Haemost 2019;119(08):1365-1372

3 Arnhjort T, Persson LM, Rosfors S, Ludwigs U, Lärfars G. Primary deep vein thrombosis in the upper limb: a retrospective study with emphasis on pathogenesis and late sequelae. Eur J Intern Med 2007;18(04):304-308

4 Levy MM, Bach C, Fisher-Snowden R, Pfeifer JD. Upper extremity deep venous thrombosis: reassessing the risk for subsequent pulmonary embolism. Ann Vasc Surg 2011;25(04):442-447
5 Tadlock MD, Chouliaras K, Kennedy M, et al. The origin of fatal pulmonary emboli: a postmortem analysis of 500 deaths from pulmonary embolism in trauma, surgical, and medical patients. Am J Surg 2015;209(06):959-968

6 Newton DH, Monreal Bosch M, Amendola M, et al; RIETE Investigators. Analysis of noncatheter-associated upper extremity deep venous thrombosis from the RIETE registry. J Vasc Surg Venous Lymphat Disord 2017;5(01):18.e1-24.e1

7 Houghton DE, Casanegra AI, Peterson LG, et al. Treatment of upper extremity deep vein thrombosis with apixaban and rivaroxaban. Am J Hematol 2020;95(07):817-823

8 Beiswenger AC, Quereshy HA, Rouabhi M, et al. Midterm outcomes in patients with upper extremity deep vein thrombosis. J Vasc Surg Venous Lymphat Disord 2020;8(06):930.e2-938.e2

9 Bleker SM, van Es N, Kleinjan A, et al. Current management strategies and long-term clinical outcomes of upper extremity venous thrombosis. J Thromb Haemost 2016;14(05):973-981

10 Delluc A, Le Gal G, Scarvelis D, Carrier M. Outcome of central venous catheter associated upper extremity deep vein thrombosis in cancer patients. Thromb Res 2015;135(02):298-302

11 Fan F, Zou Y, Zhang S, et al. Rivaroxaban in the treatment of PICCassociated upper extremity venous thrombosis. Clin Ther 2017; 39(09):1882-1888

12 Laube ES, Mantha S, Samedy P, Wills J, Harnicar S, Soff GA. Treatment of central venous catheter-associated deep venous thrombosis in cancer patients with rivaroxaban. Am J Hematol 2017;92(01):E9-E10

13 Kovacs MJ, Kahn SR, Rodger M, et al. A pilot study of central venous catheter survival in cancer patients using low-molecular-weight heparin (dalteparin) and warfarin without catheter removal for the treatment of upper extremity deep vein thrombosis (The Catheter Study). J Thromb Haemost 2007;5(08): 1650-1653

14 Davies GA, Lazo-Langner A, Gandara E, et al. A prospective study of rivaroxaban for central venous catheter associated upper extremity deep vein thrombosis in cancer patients (Catheter 2). Thromb Res 2018;162:88-92

15 Rathbun SW, Stoner JA, Whitsett TL. Treatment of upper-extremity deep vein thrombosis. J Thromb Haemost 2011;9(10): 1924-1930

16 Porfidia A, Agostini F, Giarretta I, et al. Upper extremity deep vein thrombosis treated with direct oral anticoagulants: a multicenter real world experience. J Thromb Thrombolysis 2020;50 (02):355-360

17 Frank DA, Meuse J, Hirsch D, Ibrahim JG, van den Abbeele AD. The treatment and outcome of cancer patients with thromboses on central venous catheters. J Thromb Thrombolysis 2000;10(03): 271-275

18 Prandoni P, Bernardi E, Marchiori A, et al. The long term clinical course of acute deep vein thrombosis of the arm: prospective cohort study. BMJ 2004;329(7464):484-485

19 Kearon C, Akl EA, Ornelas J, et al. Antithrombotic therapy for VTE disease: CHEST guideline and expert panel report. Chest 2016; 149(02):315-352

20 Kahn SR, Galanaud JP, Vedantham S, Ginsberg JS. Guidance for the prevention and treatment of the post-thrombotic syndrome. J Thromb Thrombolysis 2016;41(01):144-153

21 Ageno W, Riva N, Schulman S, et al; IRSVT study group. Antithrombotic treatment of splanchnic vein thrombosis: results of an international registry. Semin Thromb Hemost 2014;40(01): 99-105

22 Ageno W, Riva N, Schulman S, et al. Long-term clinical outcomes of splanchnic vein thrombosis: results of an international registry. JAMA Intern Med 2015;175(09):1474-1480

23 Delgado MG, Seijo S, Yepes I, et al. Efficacy and safety of anticoagulation on patients with cirrhosis and portal vein thrombosis. Clin Gastroenterol Hepatol 2012;10(07):776-783 
24 Turnes J, García-Pagán JC, González M, et al. Portal hypertensionrelated complications after acute portal vein thrombosis: impact of early anticoagulation. Clin Gastroenterol Hepatol 2008;6(12): 1412-1417

25 Di Nisio M, Valeriani E, Riva N, Schulman S, Beyer-Westendorf J, Ageno W. Anticoagulant therapy for splanchnic vein thrombosis: ISTH SSC Subcommittee Control of Anticoagulation. J Thromb Haemost 2020;18(07):1562-1568

26 Riva N, Ageno W. Direct oral anticoagulants for unusual-site venous thromboembolism. Res Pract Thromb Haemost 2021;5 (02):265-277

27 Simonetto DA, Singal AK, Garcia-Tsao G, Caldwell SH, Ahn J, Kamath PS. ACG clinical guideline: disorders of the hepatic and mesenteric circulation. Am J Gastroenterol 2020;115(01):18-40

28 Northup PG, Garcia-Pagan JC, Garcia-Tsao G, et al. Vascular liver disorders, portal vein thrombosis, and procedural bleeding in patients with liver disease: 2020 practice guidance by the American Association for the Study of Liver Diseases. Hepatology 2021; 73(01):366-413

29 Garcia DA, Baglin TP, Weitz JI, Samama MM. Parenteral anticoagulants: Antithrombotic Therapy and Prevention of Thrombosis, 9th ed: American College of Chest Physicians evidencebased clinical practice guidelines. Chest 2012;141(2, Suppl): e24S-e43S

30 Kearon C, Akl EA, Comerota AJ, et al. Antithrombotic therapy for VTE disease: Antithrombotic Therapy and Prevention of Thrombosis, 9th ed: American College of Chest Physicians evidencebased clinical practice guidelines. Chest 2012;141(2, Suppl): e419S-e496S

31 Key NS, Khorana AA, Kuderer NM, et al. Venous thromboembolism prophylaxis and treatment in patients with cancer: ASCO clinical practice guideline update. J Clin Oncol 2020;38(05): 496-520

32 Cohen O, Caiano LM, Tufano A, Ageno W. Cancer-associated splanchnic vein thrombosis. Semin Thromb Hemost 2021;47 (08):931-941

33 Tufano A, Ageno W, Di Micco P, et al; RIETE Investigators. Outcomes during anticoagulation in patients with symptomatic vs. incidental splanchnic vein thrombosis. Thromb Res 2018; 164:69-74

34 Cheng $Q$ Tree K. Systematic review of thrombolysis therapy in the management of non-cirrhosis-related portal vein thrombosis. J Gastrointest Surg 2021;25(06):1579-1590

35 DeLeve LD, Valla DC, Garcia-Tsao GAmerican Association for the Study Liver Diseases. Vascular disorders of the liver. Hepatology 2009;49(05):1729-1764

36 Cohen O, Pegoraro S, Ageno W. Cerebral venous thrombosis. Minerva Med 2021. ( e-pub ahead of print) Doi: 10.23736/ S0026-4806.21.07353-5

37 Bousser MG, Ferro JM. Cerebral venous thrombosis: an update. Lancet Neurol 2007;6(02):162-170

38 Ferro JM, Bousser MG, Canhão P, et al; European Stroke Organization. European Stroke Organization guideline for the diagnosis and treatment of cerebral venous thrombosis - endorsed by the European Academy of Neurology. Eur J Neurol 2017;24(10): 1203-1213

39 Coutinho JM, Ferro JM, Zuurbier SM, et al. Thrombolysis or anticoagulation for cerebral venous thrombosis: rationale and design of the TO-ACT trial. Int J Stroke 2013;8(02):135-140

40 Saposnik G, Barinagarrementeria F, Brown RD Jr, et al; American Heart Association Stroke Council and the Council on Epidemiology and Prevention. Diagnosis and management of cerebral venous thrombosis: a statement for healthcare professionals from the American Heart Association/American Stroke Association. Stroke 2011;42(04):1158-1192

41 Ferro JM, Coutinho JM, Dentali F, et al; RE-SPECT CVT Study Group. Safety and efficacy of dabigatran etexilate vs dose-adjusted warfarin in patients with cerebral venous thrombosis: a randomized clinical trial. JAMA Neurol 2019;76(12):1457-1465

42 Miranda B, Aaron S, Arauz A, et al. The benefit of EXtending oral antiCOAgulation treatment (EXCOA) after acute cerebral vein thrombosis (CVT): EXCOA-CVT cluster randomized trial protocol. Int J Stroke 2018;13(07):771-774

43 Hayreh SS, Zimmerman MB, Beri M, Podhajsky P. Intraocular pressure abnormalities associated with central and hemicentral retinal vein occlusion. Ophthalmology 2004;111(01):133-141

44 Raslan OM, Lazo-Langner A. Treatment of retinal vein thrombosis: what about anticoagulants? Minerva Med 2021. ( e-pub ahead of print) Doi: 10.23736/S0026-4806.21.07474-7

45 Pulido JS, Flaxel CJ, Adelman RA, Hyman L, Folk JC, Olsen TW. Retinal vein occlusions preferred practice Pattern( $\left({ }^{\circledR}\right)$ guidelines. Ophthalmology 2016;123(01):182-208

46 Schmidt-Erfurth U, Garcia-Arumi J, Gerendas BS, et al. Guidelines for the management of retinal vein occlusion by the European Society of Retina Specialists (EURETINA). Ophthalmologica 2019; 242(03):123-162

47 Ageno W, Beyer-Westendorf J, Garcia DA, Lazo-Langner A, McBane RD, Paciaroni M. Guidance for the management of venous thrombosis in unusual sites. J Thromb Thrombolysis 2016;41(01): 129-143

48 Lazo-Langner A, Hawel J, Ageno W, Kovacs MJ. Low molecular weight heparin for the treatment of retinal vein occlusion: a systematic review and meta-analysis of randomized trials. Haematologica 2010;95(09):1587-1593

49 Belcaro G, Dugall M, Bradford HD, et al. Recurrent retinal vein thrombosis: prevention with Aspirin, Pycnogenol ${ }^{\circledR}$, ticlopidine, or sulodexide. Minerva Cardioangiol 2019;67(02):109-114

50 Rodriguez P, Belcaro G, Dugall M, et al. Recurrence of retinal vein thrombosis with Pycnogenol ${ }^{\circledR}$ or Aspirin ${ }^{\circledR}$ supplementation: a registry study. Panminerva Med 2015;57(03):121-125

51 Shi W, Dowell JD. Etiology and treatment of acute inferior vena cava thrombosis. Thromb Res 2017;149:9-16

52 Watson L, Broderick C, Armon MP. Thrombolysis for acute deep vein thrombosis. Cochrane Database Syst Rev 2016;11:CD002783

53 Vedantham S, Goldhaber SZ, Julian JA, et al; ATTRACT Trial Investigators. Pharmacomechanical catheter-directed thrombolysis for deep-vein thrombosis. N Engl J Med 2017;377(23): 2240-2252

54 Comerota AJ, Kearon C, Gu CS, et al; ATTRACT Trial Investigators. Endovascular thrombus removal for acute iliofemoral deep vein thrombosis. Circulation 2019;139(09):1162-1173

55 Alkhouli M, Zack CJ, Zhao H, Shafi I, Bashir R. Comparative outcomes of catheter-directed thrombolysis plus anticoagulation versus anticoagulation alone in the treatment of inferior vena caval thrombosis. Circ Cardiovasc Interv 2015;8(02):e001882

56 Asghar M, Ahmed K, Shah SS, Siddique MK, Dasgupta P, Khan MS. Renal vein thrombosis. Eur J Vasc Endovasc Surg 2007;34(02): 217-223

57 Kodali N, Veytsman I, Martyr S, Lu K. Diagnosis and management of ovarian vein thrombosis in a healthy individual: a case report and a literature review. J Thromb Haemost 2017;15(02):242-245

58 Bannow BTS, Skeith L. Diagnosis and management of postpartum ovarian vein thrombosis. Hematology (Am Soc Hematol Educ Program) 2017;2017(01):168-171 